This is an electronic version of an article published in Equity and Excellence in Education, 2004, volume 36, number 1, pages 5-14. Equity and Excellence in Education is available online at: http://journalsonline.tandf.co.uk/openurl.asp?genre=article\&id=doi:10.1080/10665680303506 Reprinted with permission.

\title{
Social Perspective Taking: Advancing Empathy and Advocating Justice
}

\author{
Francisco Rios, Allen Trent, and Lillian Vega Castañeda
}

National demographic changes and current educational policies are in conflict. The consequences of this conflict, if not resolved, will be long-lasting and detrimental. Our nation is rapidly becoming more diverse - ethnically, racially, and linguistically. Recent educational trends, however, signal a move away from responsible actions that would honor and address the increasingly diverse populations in our public schools. As teacher educators, we seek to understand the public dialogue pertinent to this conflict, to facilitate the education of "culturally relevant" teachers (Ladson-Billings, 1992), and to investigate whether there is merit in a specific "social perspective taking" activity we conducted in our university courses.

Newly released Census 2000 data documents "explosive" growth in Hispanic, non-Hispanic Black, Asian, and American Indian populations in the U.S. (Armas, 2001). According to the USA Today "Diversity Index," ethnic minority populations are up 23\% as compared to 1990 Census data. Some argue that these numbers are probably underestimated (El Nasser \& Overberg, 2001). These population trends have been mentioned by University of Michigan demographer William Frey as a "celebration of our diversity that's always been at the core of our society" (Armas, 2001, p. 2).

Alternatively, recent educational trends and policies seem to ignore or dismiss the increased ethnic and racial diversity present in our nation's classrooms. A recent study of multicultural education conducted in a large Midwestern school district finds that "the multicultural education reform movement is in peril" (Bohn \& Sleeter, 2000, p. 156). Why, with the earlier noted "explosive" growth in diverse racial and ethnic populations in this country, would multicultural education and attempts to honor and meet the needs of these diverse populations be in "peril?" Consider the analysis provided by Bohn and Sleeter:

Both teachers and administrators in the [studied] school district blame new state standards and anticipated state assessments, which have put pressure on school districts to standardize and emphasize content at the expense of any other concerns. Conversations we've had with colleagues around the country suggest that this is not an isolated phenomenon. Multicultural education appears to be in very real danger of getting shelved as the preoccupation with national and state standards testing intensifies.

Those monitoring the effects of the standards movement on multicultural education are deeply concerned that the development of new standards is occurring in an increasingly repressive environment (p. 156).

Indeed, we are left to wonder if the net effect of standards will be the standardization of teacher and student thinking.

Other recent education related actions and policies highlight the pervasiveness of xenophobic attitudes. In California, the passage of Proposition 227 eliminated bilingual education despite the fact that language diversity in the state continues to increase exponentially. Ron Unz, the man who claims credit for "dismantling bilingual education" in California, spearheaded a similar "successful" initiative in Arizona and now has his sights set on passing an initiative to eliminate (or seriously limit access to) bilingual education in a handful of other states (Hubler, 2001).

These xenophobic actions are not directed only at P-12 public schools. The Colorado Commission on Higher Education recently commissioned the National Association of Scholars (NAS) to conduct "an objective evaluation of state teacher education programs" (Curtin, 2001, p. IB). The NAS recommended that the teacher education program at the University of Colorado (CU) be suspended because of its agenda that focuses on "issues of race, class, gender, and sexual orientation." The NAS report "blasts" CU for being "the most politically correct and stridently committed to the social justice model" (Curtin, 2001, p. 3B). As teacher educators, we applaud the efforts of those at CU. We seek similar "critiques" of our 
institutions. We believe that diversity in our nation's classrooms - for example, ethnic, racial, gender, and sexual orientation diversity — provides the impetus for us, as educators, to focus on multicultural education, the centering of marginalized perspectives, and educational systems that are equitable and socially just.

We seek to nurture, in ourselves and our students, attitudes and dispositions that go beyond superficial mul-ticulturalism. This superficiality is often evidenced in multicultural education efforts that have been referred to as a "heroes and holidays approach" (Lee, Menkart, \& Okazawa-Rey, 1998). Such approaches lead to student marginalization, ethnic disfiguration, willful not learning, and academic failure (Kohl, 1994; McCarthy, 1998). It is hard not to wonder if xenophobic policy makers purposefully seek these goals.

We are advocates for a substantial response aimed to increase the number of teachers with cross-cultural understanding so that the above effects might be avoided. Goals must include facilitating teacher education programs that foster cross-cultural understanding, supporting the development of informed advocacy positions, and fostering teacher attitudes and actions that honor and value students from diverse backgrounds traditionally marginalized by racist institutional policies and practices. Teaching "otherness" holds promise in meeting these goals.

\section{TEACHING "OTHERNESS"}

"Teaching otherness" connects teachers' lives to difference and similarity (Kanpol, 1992). Additionally, it seeks explicit connections between ideology and practice as they relate to issues of race, class, ethnicity, and gender. The hope is that teachers will understand, embody, and become advocates for social justice and, in turn, transfer this perspective to their students as a way of understanding and improving society. One aim includes a redefinition of democracy itself. This, we assert, can and should happen through a coupling of critiques of existing injustice with a new, hopeful vision of the possibilities inherent in an emancipatory politic (Kanpol, 1992).

More specifically, we have pursued these aims in a variety of ways in our university courses. Of primary importance is the use of narratives since they serve as the "primary act of the mind" (Hardy, 1977, p. 1). We think in narratives, and therefore, narratives show us the complexity, irony, and ambiguity of life as we know it (Coles, 1989). By engaging narratives of "others," we are provided with alternative worldviews that enable us to challenge/trouble our own. Through the use of narratives, readers situate themselves in the other and then determine degrees of connectedness. Narratives are powerful and accessible. Narratives are akin to what Latinos call testimonio described as a bearing witness, "a secular, spiritual testimony... with the overt intention of raising consciousness" (Chamberlain \& Thompson, 1998, p. 6). By employing narratives, read and written, we attempt to broaden perspectives. The change we desire includes the movement across a continuum from self-awareness to cross-cultural effectiveness (Locke, 1988).

\section{IMAGINING THE POSSIBLE}

In pursuit of cross-cultural effectiveness, we begin from points focused on self-development. Indeed, much of the target for cross-cultural growth is focused on the "inner" work of multicultural growth (Howard, 1999). Locke (1988) advances one model that has been instructive in this work. Briefly, Locke suggests six levels of awareness beginning with awareness of the self and directed to the endpoint: crosscultural effectiveness. The stages are awareness of self; awareness of one's culture; awareness of "isms" and poverty; awareness of individual differences; awareness of other cultures; and awareness of diversity.

In our efforts to promote cross-cultural effectiveness that moves beyond awareness and is linked to an advocacy orientation, we have attempted to use social perspective-taking activities as a principle pedagogical tool. We believe that a social perspective-taking stance can be equally robust and revealing in predominately Euro-American classrooms as well as in ethnically heterogeneous classrooms. Importantly, we are working to identify the salience of social perspective-taking when employed multiple times, across multiple issues, and carried out in multiple ways. For example, besides the strategy we employed to gather information for this study (to be explained below), we have asked students to write their auto-ethnography as juxtaposed to that of someone unlike them (in terms of ethnicity, at a minimum). As another example, we have two roleplays in which students participate (one related to the integration of schools in the 1950s and one related to institutional racism that highlights how some people are privileged and others become oppositional about schooling as a result).

In a sense, we are guided by an activity model (see Figure 1) that provides a scaffold for assuring that we pay attention as much to the social self as to the individual self and as much to the professional self as to the personal self. As can be seen, this activity model provides four distinct quadrants that we have found 
helpful in giving vision to our work around social perspective taking.

Personal Selves

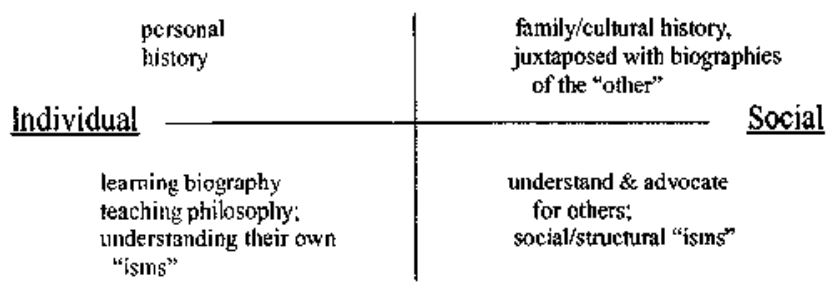

\section{Professional Selves}

Figure 1

A theoretical model for learning activities: Personal/ professional by individual/social with examples of activity for each quadrant.

\section{The Context}

Before detailing this specific social perspective-taking activity and corresponding data analysis, we describe the two settings where we collected data.1 In the first setting (A), data were collected from students, principally college-level sophomores and juniors in two education classes. One of the classes focuses on educational foundations and multicultural education (Al). The other focuses on curriculum and instruction (A2). Both classes are part of a teacher credential program that attempts an "infusion-only" model of multicultural education. It is situated in a college and university community where only about $10 \%$ of the student population is ethnic minority. The general feeling is that there is "just not much" diversity in the state or in this land-grant university located in the eastern front range of the mountain states.

The second setting (B) also encompasses students from two distinct classes at a state university in the Pacific southwest. One class is comprised of students, principally upper-division (university level juniors and seniors), in a required stand-alone course on multicultural/ multilingual education as part of a prerequisite to the teacher education program that also attempts to infuse diversity throughout $(\mathrm{Bl})$. The second class is a Master's of Art class and is best described as an advanced course in multicultural context (B2). This university is best described as moderately multicultural since about $30 \%$ of the students and faculty come from ethnic minority communities. While there is much diversity in the community (certainly greater than is represented in the university), there has been significant antagonism around the diversity efforts on the campus including the loss of several minority (primarily Latino) administrators, faculty, and staff.

Thus, within our four data groups, we have two from a minimally diverse setting and two from a moderately diverse setting. Three of the data sets reflect three undergraduate level courses; one is graduate level. Three of the courses had a distinctly multicultural orientation.

\section{A Social Perspective-Taking Activity}

The activity upon which this paper rests begins with a short introduction in which we inform students that they will be asked to take "the role" of one of two professionals who is being interviewed on videotape. In the first part of the video (about 8 minutes) a Chicano writer (Victor) describes his anger at being denied his language and culture when he was a student in an elementary classroom. In the second part (about 15 minutes), a Chinese scholar of bilingual education (Lily) goes back to her elementary school and local community where she recalls painful experiences about not understanding English and not being included in the elementary classroom.

After watching the video, students are asked to write a letter to a teacher, from either Lily or Victor's perspective, and to begin the letter: "Dear Teacher, If only you knew___ This provided the first tier of our analysis. The second part of this activity occurs after the letters are collected. They are randomly distributed back to the class. The students are asked to imagine themselves as teachers, to imagine having received this letter in their mailbox. They are asked to write down what they would think, what they would feel, what they would do. This provides a second and, to us, more significant tier of analysis. The letters 
and the teachers' responses are the basis for both tiers of analysis described here.

Analysis One: "If Only My Teacher Knew___ _ We looked first at the letters written by the students from either Lily or Victor's perspective to their teacher. Students easily could position themselves in either Lily or Victor's shoes, both cognitively and/or emotionally. We argue that much of this is related to having written a letter after just having seen a video of the characters whose perspective they were taking. We noted that students tend to respond emotionally along a continuum from "I'm happy now," to neutral feelings, to frustration, embarrassment, pain, and rage. Often they expressed multiple emotions including what they had felt (in the past) and what they are feeling now (in the present). We note that much of the emotion varied depending upon whose perspective they took (Victor's emotional displays, of anger, sadness, and joy, are more intense than those of Lily).

The second finding about these initial letters is that they posit intentionality; that is, they offer the social perspective-takers' thoughts about why they think the teacher behaved as she did. The students were, we believe, trying to make sense of why these events occurred. Again, the continuum went from "It's not your fault" to causes that move from benign neglect, to ignorance, to purposeful wrong-headedness (the most frequent response), to outright racist and discriminatory intentions.

Consider the following excerpt from one letter:

To my teacher:

If only you know the pain that you put me through. You and your prejudices forced me to dwell within myself. You forced me to be someone just to spite you. When you told me that my language and culture weren't good for anything, you opened a wound in my soul. This wound forced me to hate myself and everything I represent. I have made it my goal in life to become someone just so that my children don't have to suffer the same humiliation that I felt when I was their age (Al).

In this letter, we can see the emotional display of anger and pain expressed by this writer when writing from Victor's perspective. Notice also the positing of "prejudice" as the explanation for the teacher's behavior.

Analysis Two: "Dear Student." While these first letters were informative, we were especially taken by the responses engendered to the letters that were the second part of this assignment both because of what these revealed about the respondents as well as the variation in responses received. Consider the following two responses as examples:

\section{Dear Victor:}

I am amazed at your success in life. I was not expecting that. I had not expected anybody of your race would succeed on their own and still have their own culture. I tried to mold you into who I thought it would take to survive in the world. That is the reason why I told you "none of that Mexican stuff." In the America of then a person of Mexican descent could not find a good job, so I was trying to let you succeed in that time, how was I supposed to know that society would change and my behavior would become unsympathetic to you and your race? Besides you must ask yourself this single question, "Where would I be in my life if it wasn't for the pain my teacher put me through?" I think that you will discover at the end of that questions that I was your inspiration, and without me your life would be incomplete. If it wasn't for me you would be nothing, therefore I won in the end. I directed your life, I am you and you are me (Al).

Dear Victor,

Looking back I can see how wrong I was in treating you the way I did. Not only you, but also the other minority children. I know no words can express how sorry I am, nor change what happened. I think about you and my other students in your situation a lot. I regret the way that I treated you. I am also so proud of you now, for being Mexican, for being successful, even though you did not have positive influences in school. I give you my sincerest apology and my greatest wishes for your success (Al).

As we read these letters, we argue that the students' authentic selves emerge (since it's more distant from the video) and since they do not have an image on which to rely outside of their own imagination of themselves as teachers (in the case of the students in the graduate program, most of whom are teachers, that 
image is more real). Because of this, we have spent the bulk of our own activity carefully analyzing this second tier of responses.

\section{DATA CODING/CATEGORIZING/EMERGENT FINDINGS AND THEORIES}

To code/interpret these second letters (response from teacher to Victor or Lilly) such as the two above, we initially employed an emergent, grounded theory approach (Glaser \& Strauss, 1967). In other words, our initial examinations and theoretical assertions were anchored in the specific data sets. We then mapped these initial themes onto existing frameworks, and ultimately juxtaposed and melded a series of frameworks to develop more robust and appropriate categories that allowed us to aggregate coded data and formulate theoretical assertions.

\section{Grounded Analysis}

In analyzing these responses to the "If only you knew " letters, most people provided a letter in response. Within these letters, we saw that the respondents often tried to explain why they acted as they did. These explanations provided us with our initial, grounded framework for analysis. The varied responses were grouped according to the following categories:

- I helped you; you should thank me

- It's not my fault

- I'm really sorry (the most frequent response)

- I just didn't know what to do

- I was doing the best I could and thought this was in your best interests

- I understand how difficult this might have been

- I genuinely understand the problem and inappropriate-ness of my actions, and the related systemic failures.

One thing we noted was that while students in their first letters most frequently blamed the teachers for "purposeful wrong-headedness," the responses back (often) simply apologized and explained it as lack of information or the social/cultural milieu of the time.

Frequently, responses hinted the incident required no future action. However, some of the respondents also suggested some course for future action. The course of action was usually driven by the explanation the person provided for why they acted as they did. Thus, when a course of action was proposed, the responses varied from changing the individual's behavior to the initiation of broader scale school-wide discussion and action. Consider the following two letters which have both explanations and propose distinct courses of action (the first a personal action response; the second a school-wide/institutional response):

\section{Dear Victor:}

I was happy to receive your letters, however, distressed to discover the damage I had done. I had no idea how you were feeling. In my eyes, I believed by encouraging you to use English as much as possible you would pick up the language more easily - which in turn would help you through school and years beyond. It is with your letter that I understand the depth of which my actions affected you. I now realize I must encourage everyone in my class and for this to take place we must learn to appreciate each other and our backgrounds. From now on, I will include multicultural instruction in my teaching in hopes of instilling the same pride in my children as you have found in yourself today (Al).

Reaction to the Victor Letter:

My first reaction this letter would be an awful, sick feeling. As a teacher, I hate to think that I had such a horrible, negative experience on one of my students, and probably many, many more. I would have deep regret for my ignorance. I would then maybe feel a little relief that he had overcome what I did to him (whether intentionally or ignorantly). I would be happy for his successes.

The next thing I would do is sit down and write a letter of apology to Victor. I would express my deep regret and sorrow for the pain and confusion I had caused him and sincerely ask for his forgiveness if that would ever be possible. I would also congratulate him on all his wonderful achievements and success.

Finally, I would take this letter to our next faculty meeting and read it to all the faculty. I would express regrets to them and ask them to help me and join with me in a new concentrated effort to improve equity in our school and 
stop hurting children (Al).

\section{External Frameworks}

After creating a data-driven framework for analysis, we were curious to seek alternative ways to analyze and interpret the data and found two extant frameworks. First, we considered a taxonomy designed to assess pre-service teachers' attitudes and orientations toward multicultural education. For that, we considered the Affective Taxonomy for Multicultural Education (Rios, McDaniel, \& Stowell, 1998) (see Table 1). Indeed, in our informal analysis, many of the second tier responses could be coded into these taxonomic categories. Nonetheless, we pursued a second external framework as a frame for analyzing/interpreting the data. Kivel (1996) worked extensively with violent men and noted a common series of tactics they employed to avoid taking responsibility for their actions (see Table 1). Later, Kivel realized that this series of tactics was being utilized in a variety of contexts to explain or justify already existing injustice or violence. We, in turn, considered this series of tactics for avoiding responsibility to our data sets. Again, much of our data, when juxtaposed with Kivel's list, corresponded with the various tactics used for avoiding responsibility.

Table 1

Complementary Taxonomies Regarding Responses to Issues in Diversity

Affective Taxonomy for Multicultural Education (Rios, McDaniel, \& Stowell, 1998)

- Racist/Hostile - Openly opposed to issues of diversity, multiculturalism, bilingualism, etc.

- Denial—Denies or questions the need for a focus on diversity/multicultural education

- Awareness - Suggests that multicultural education is about increasing awareness-understanding (via knowledge)

- Minimizing Negative Reaction-Focuses on minimizing bias, prejudice, stereotypes, etc.

- Integration-Suggestions that multicultural education is about having people be integrated, get along, work together, etc.

- Acceptance_-belief that multicultural education should foster acceptance/respect for people who are diverse, speak multiple languages, etc,

- Valuing - Shows a deeper degree of passion (appreciation, championing, etc.) for multiculturalism, bilingualism, and diversity

- Commitment to Social Justice_-Feeling so strongly about cultural and linguistic diversity that the person is willing to act to promote a more fair, just society

Retaining Benefits-Avoiding Responsibility (Kivel, 1996)

- Denia/—Denial of actions allows one to avoid responsibility

- Minimization-Minimize the intensity of the actions

- Blame-Claim the action is justified by "blaming the victim" (often using biological or psychological justifications)

- Redefinition-Assume the action is justified by redefining the situation as individual or local while minimizing the role of power differentials and the overall context

- Unintentionality - Claim that the actions was unintentional and the responsibility is minimized irrespective of any pattern of action

- it's Over Now-Defuse responsibility by claiming if only happened in the past and is no longer an issue

- It's Only a Few People —Claim that It's only a few people or Isolated incidents and therefore not systemic not institutional

- Counterattack \& Competing Victimization-A claim of the reversal of power relations and that the actor Is more of a victim than the actual victim of abusive behavior

Ultimately, however, we realized an integration of frameworks was the most productive way for us to analyze/interpret our data and this integrated framework would better assist us in generating theoretical assertions. We revisited our initial grounded categories, the Affective Taxonomy for Multicultural Education (Rios et al., 1998), and Kivel's (1996) tactical list, and created our final, integrated framework for second tier data analysis/ interpretation. This framework included categories for deconstructing the explanations, justifications, and rationalizations of the "teacher" respondents. These are the amalgamated categories for responses with examples from the data for each: 
A) Racist/Hostile-Included responses that counterattacked, blamed the student for the problem, or sought "competing victimization" ("I'm a victim, too"); You have to try harder to learn English if you really want to learn in school. I'm trying to help you, bu tit's really hard for me, too (B2); The fact is you and your people are in the United States and English is spoken here. So if you want to get educated, speak English. I am busy enough planning lessons and preppingfor them. The last thing I need is for someone to think I am not doing my job. If you cannot speak the language, go back to Mexico (B2); Cut us severely ignunt white folks some slack (A2).

B) Denial-Included responses like "This didn't happen," "It happened, but it wasn't my fault," and other denials of responsibility; I had a job to do and that is what I did, I was responsible to teach you English and that is what I did. I hope that you can get over your pain and embarrassment (B2); At the time you were enrolled in my class, as teachers we were not formally educated on multiculturalism andhow to integrate various cultures into our lesson (Bl).

C) Minimization-Included redefinition of the problem, posited unintentionality, assertions of, "This is no longer a problem," and claims that the teacher's actions were for the student's own good; With all due respect to you as a person and your culture, it was your best interests I had in mind (Bl). As far as sayings like, "None of that Mexican stuff," I surely was not insulting you. I just did not want you goofing around (Al); Hopefully you have some good memories of "our" classroom as well (Al).'

D) Awareness-Included responses of sorrow, remorse, genuine understanding, and empathetic explanations of past actions; I am sorry to hear how I have hurt you. I can only attribute my cruelty to my own ignorance. I hope that I am older and wiser now, but I still cannot undo the damage that I have

done (B2); 1 was self-centered and unaware _ I'm sorry, I did

not realize the hurtful way I treated you. I am grateful for your honesty and for your courage it took to write me (Al),

As teacher educators, we aim to foster /support an advocacy orientation in our students. In addition to the coding of the explanations, justifications, and rationalizations of the "teacher" respondents (discussed above), we developed this separate series of categories for coding the posited "action orientation" of the individual:

W) No Action-Individual responses that the "teacher" respondent did not refer to any further action, personal or otherwise.

X) Individual Action - Individual responses that posit an intention to act individually; I am happy to report that in the last 5 years, many improvements have been made. I have attended numerous diversity workshops and am learning how to teach towards an audience of all cultures and ethnicities (Bl); I would like to learn more about your language and culture. Perhaps you would like to share with the class some facts about your background. I can set aside some time for us to listen $(B \mathrm{l})$.

Y) Systemic Action-Included responses that posit specific actions to be taken on school-wide and/or systemic levels; / will make a point to advocate for non-English speakers and if you don't mind, I'd like to share your letter with my co-workers, some of them need to also be enlightened (Bl); It will be my number one goal to bring bilingual education to the attention of as many educators as possible. I plan to start immediately within my own classroom and then go directly to the principal at the school where I teach (Al).

This framework proved most effective for coding, analysis, and interpretation. Two teaching team members reanalyzed the data given the framework to quantify the number of times student comments appeared for each category in their responses to the student letter. The two independently counted the number of instances of words, phrases or whole sentences indicative of each category. They then met to discuss areas of disagreement or omission by one or the other, clarifying the categories and arriving at complete interrater agreement. Some responses fit more than one category, and therefore were "cross-coded" as such.

The data from this analysis, with respect to the four cohorts of students is summarized in Table 2. Two findings are immediately evident to us in viewing this data. First, the level of hostility by the respondents in the more culturally diverse (B) of the two contexts stands out. Perhaps the adage "familiarity breeds contempt" best explains this result. Indeed, in recent years, voters in this state have supported political propositions that can be classified as anti-immigrant, anti-affirmative action, and anti-bilingual education. Indeed, we wonder if this state-wide action is giving these students/teachers the invitation to express their own anger and hostility at the "marginalized others." On the other hand, the responses in the less diverse state (A) speak much of the "live and let live" orientation (implied is "don't ask, don't tell") as well as "rugged individualism" that is part of the political culture. Perhaps this explains the denial reaction as well as the taking action on the individual level that is evident in these (A) data counts.

Second, we were struck by the responses between the one teacher group (B2) and the three "preservice" teachers groups (Al, $\mathrm{A} 2$, and $\mathrm{Bl}$ ). We note that the teacher group was less likely to offer some action/advocacy for the student than were the other three groups. Perhaps this lack of action by the in- 
service teacher group was a result of their own exhaustion on the day the sample was gathered (Class began at 5:30 p.m., ending at 8:00 p.m., and most of the teachers had been teaching all day; all three of the other classes took place during the 8:00-5:00 p.m. time slot). Perhaps being part of the school system, they are less optimistic that anything will really matter and, given their experience, a belief that change is too difficult to achieve. In contrast to this pessimism, we note the preservice groups were more likely to take action indicating, perhaps, greater optimism, greater energy, and a greater sense of hopefulness. We note that all four groups, however, were much more likely to take individual action than to move to the schoolwide or society-wide level of advocacy.

Table 2

Response Count, Four Cohorts of Students by Response and Future Action

\begin{tabular}{lcccc}
\hline Cohort response & Al $(n=19)$ & A2 $(n=17)$ & B1 $(n=21)$ & B2 $(n=15)$ \\
\hline Racist/hostile & 0 & 2 & 4 & 5 \\
Denial & 1 & 1 & 3 & 4 \\
Minimization & 13 & 7 & 16 & 10 \\
Awareness & 18 & 13 & 19 & 11 \\
No actlon & 9 & 3 & 9 & 10 \\
Individual action & 9 & 14 & 12 & 5 \\
Lacal action & 4 & 2 & 0 & 1 \\
System-wide action & 0 & 0 & 1 & 0 \\
\hline
\end{tabular}

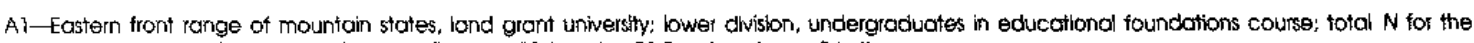
course: 25; oges 19-26; preservice only: 7 males, 18 temales; 23. EuroAmerican', 2 Latincs.

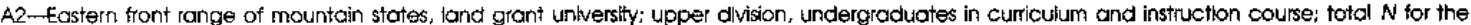
course: 17: ages 20-45: preservice only: 14 males. 3 females: 76 EuroAmericans, 1 Nathe American.

E : - Pacific southwest, state unlversity; upper division undergraduates in multiculturo/second language learning course; totol $N$ for the couse: 30 ; 0 ges 20-55; preservice and inservice tegchers; 13 males, 17 femdes: 21 EuroAmericons, 5 botinos. 2 Africon Ameriogns, 1 Biraclal, 1 Chinese.

B2-Pocitic southwest, stote university: graduote level advanced course in multicultural/multilingual education; total $N$ for the course: 20 ; ages 24-60: trservice only: $A$ moles, it femoles: 13 Eumomericons, 6 Lotinos. 1 koregr.

\section{THEMES, THEORIES, AND THOUGHTS}

In this article, we have attempted to employ a pedagogical tool, social perspective-taking, as a way to engage our students in the act of critical self-reflection, from a personal and professional point of view. The use of perspective taking devices, especially around issues of diversity (e.g., race, class, gender, ethnicity, and language) is useful in our work as teacher educators who care about social justice. It allows us to engage our students in activity that draws upon their insider knowledge (e.g., what it is to be a member of a given group, whether it is privileged or disadvantaged) and lived experiences. It allows for simultaneous processing of information when students are asked to take on the perspective of a definable "other." Students are moved to consider their position, privilege (or lack of), and experience as both student and teacher. By assuming the position of "other," we argue that students are forced to become consciously aware and awakened to their specific location as they adapt an identity mediated by life experiences different (in many cases) from their own. Via social perspective-taking, we seek to create a three-tiered process incorporating awareness, analysis, and advocacy. The attempt is to move our students to first, become awakened to their particular place in society (which we hope includes an explicit examination of their own position and privileges) and that of the "other" (awareness). Secondly, we engage our students in reflexive analysis (Hammersley \& Atkinson, 1995). And finally, it is our hope that this type of work will move our students toward action for social justice, and advocacy orientations integrated into their teaching repertoire.

Social perspective-taking may move future and current teachers to consider and challenge their understandings as well as their (explicit or implicit) acceptance of teaching philosophies/notions associated with deficit understandings, disadvantage, advantage, privilege, and oppression. This pedagogical tool allows for reflection and ongoing questioning of participants' personal and professional selves. It combines an integrated, reflective focus on both cognitive and affective aspects of students' personally held theories. Importantly, this could move individuals toward the formulation of propositions associated with teaching and learning that challenge their beliefs. We agree that people's social, political, and cultural experiences contribute to shaping their approach to teaching and learning. But it is our hope that we engage our own 
students in such a way that they are moved to learn about their present and future students. Given that our nation's teaching force is mainly white and female, we believe this type of activity is useful in helping to raise teacher candidates' personal awareness to issues surrounding difference; our hope is to provide illuminating information about what it is like to be disenfranchised.

Yet, we do not see social perspective taking as a panacea. We continue to express our own frustrations and entertain questions from colleagues about the limitations of social perspective-taking. We do not assume that we can change anyone's mind or way of thinking; our attempt is to involve students experientially in these activities, encouraging reaction and reflection. Additionally, we believe it is too difficult, due to the number and interaction of a variety of factors, to predict how long individuals might resist or deny the experiences of "the other." Clearly, as a society, we collectively resist an understanding of the "other" in a variety of ways, daily, for years upon years. Other factors include the following: the idiosyncratic growth and development of individuals; the kind of sociocultural experiences of the participants; the individuals' personalities and identity constructions; and the length of time and number of opportunities to participate in experiences in which participants encounter the other. Equally important, what people resist, interpret, or understand is connected to their conscious (free) will as are their decisions to act in concert (or not) with this conscious will. Thus, pinpointing a point in "real time" as to an individual's length of time spent "resisting" is neither in our ability nor in our intent. Still, we remain hopeful that people, given appropriate experiences and scaffolding, can move forward in developing empathetic, advocacy oriented perspectives.

Specifically, consider the difficulty of facilitating social perspective-taking on the part of current and future teachers as explained psychologically, socially, and culturally. Psychologically, individuals resist having to consider information that challenges their own thinking and, most especially their self-image. Piaget (Piaget \& Inhelder, 1958) argued that individuals seek a state of equilibrium. Experiences that counter the individual's existing schemata create disequilibrium (Inhelder \& Piaget, 1958). Festinger (1957), like Piaget, argues that individuals tend to find problematic anything that creates a cognitive dissonance. These complementary theories suggest that individuals avoid or rationalize things that upset their current ways of thinking about the world. In some instances, however, when the individual does not "shut down," there is an opportunity to reorganize one's thinking to accept (that is, accommodate) this new, conflicting information. Our challenge is to find the contexts that allow for the greater possibility of cognitive reorganization.

We also would argue that cognitive factors alone are insufficient to explain the barriers to social perspective-taking. Social factors are equally important to consider. There are too few opportunities for prospective teachers who are white and middle class to have meaningful opportunities for cross-cultural interaction where, importantly, they can authentically experience what it is to be "other" without voice, power, privilege, or position (that is, to experience what it is to be a member of an oppressed group). This is especially true today given the resegregation of schools and communities. Moreover, when such opportunities do arise, rarely is the context one in which power relations are equalized, where there is a common, negotiated goal, where there is time to learn about each other, or where collaborative reflection can take place that might allow for the voicing of alternative points of view and mediation of these differences. More frequently, for example, the teacher tells the family what they must do; the teacher has a distinct agenda and ideal solution; and there is little time for anything more than accomplishing a task.

In addition, cultural factors can sometimes also be a barrier. We must first recognize that our social perspective taking can reach only varying levels of approximation of the "other's" experience. Even more, we can never fully divorce ourselves from the axiological, ontological, or epistemological lenses to which we have been socialized. We will always see things through our own cultural lens to some degree. This is especially true given the lack of opportunity in this society to interrogate these lenses since, for EuroAmericans, they represent the "norm" and are taken for granted and normalized in the policies and practices of our social institutions. Additionally, the dominant Euro-American value orientation of "individualism" creates an added barrier given that social perspective-taking relies, as it does, not on the individual self but rather on the "other" in a broader social, political, and cultural context.

All of the above factors related to the individual must also be situated in the larger political landscape that either facilitates the denial/minimization/dehumaniza-tion of the others' experiences with its concomitant "blaming of victim" mentality or counteracts it. For example, the U.S. political landscape seems to have nurtured a climate where it is appropriate for "others" to become scapegoats for the larger economic turmoil that often results in the loss of employment opportunities to the global marketplace (e.g., the debates around the North American Free Trade Agreement). Rather than blaming capitalism, globalism 
(broadly), or the obsolescence of one's skills to meet the new marketplace demands (necessitating retraining), it seems easier for some to make racial/cultural/ethnic groups the scapegoats. This has manifested itself most recently via attacks on affirmative action, immigration, and bilingual education as the root cause of the loss of economic advantage. Even though these attacks have been contested by ethnic minority communities, in such a political climate it is easy to understand the lack of a desire to understand the perspective of social-cultural groups to whom our social ills have been directly attributed.

\section{For the Future}

As we reflect on this piece, we understand that we are touching just the surface of social perspectivetaking as a potentially powerful pedagogical tool with limitations. Most hopefully, we see this activity as one that gets us, and our students, into the process of working toward awareness, analysis, and advocacy. This pedagogy demonstrates potential to incorporate active engagement leading to a critical analysis of personal responses to social perspective taking activities while subsequently allowing for working beyond personally held theoretical positions to respond on levels that are consistently oriented to advocacy and justice. To achieve this coherent set of "into, through, and beyond" activities, future and continued work in this area is needed. For our part, we will consider analysis of responses nested within demographic data with respect to age, gender, ethnicity, and number of years in teaching. In the future, we will add another level of analysis in which we utilize students' personal histories juxtaposed in a framework of "the downside of advantage." These data will allow a deeper level of analysis. We also wonder what it would look like if we gave our students the framework that emerged in the data analysis described in this article and asked them to take a perspective on a specific issue and then act on the problem at an individual, and then, systemic level. This could be further extended into role-play situations with critique of responses from members of the classroom.

We wonder what the cumulative effects of multiple perspective taking would be. If we consider that philosophy of education may be defined by multiple socio-political frames, we could ask students to crossreference and analyze their adopted/assigned positions to fit within a (for example) traditional/conservative, progressive, or liberatory/critical structure. The opportunity for self and professional "inner" work put side by side a perspective taking adoption of "other" holds great potential.

As a future endeavor, we are interested in developing case studies of our white students based on their privilege and position. We are especially interested in looking at white male privilege, and the awakenings in some of our students. In our experience, some of our white male students, as verified in their personal histories, are vocal about their privileged status. Some have spoken about their awakenings around issues of difference and disadvantage; generally they have experience living in culturally and socially varied milieu. Several have lived experiences as Peace Corps volunteers, speak a second language, and travel back and forth to their respective adopted countries. Others have attributed their advocacy to their peripheral and direct involvement in issues surrounding gender equity and sexual and social orientation (for example, developing robust friendships with people from marginalized groups). This type of work will allow for yet another level of much needed analysis and would potentially contribute to the development of ally formation within K-12 schools.

Growing up as disenfranchised or privileged has a profound relevance to teaching and learning. This impacts our daily work as teachers and students. For some, there is adeptness at moving between different worlds; for others the opportunity to move between different sociocultural contexts is not quite so easy. Social perspective-taking allows our students the opportunity to explore privilege and advantage while simultaneously moving them to an awareness of difference and an accompanying problem-posing and action-oriented approach to teaching and learning (Shor, 1987). As Freire (1987) described it:

It is activity that reinforces our belief that education is not a neutral process: The identical and neutral role for all teachers could only be accepted by someone who is either naive or very clever. Such a person might affirm the neutrality of education, thinking of school as merely a kind of parenthesis whose essential structure was immune to the influences of social class, gender, or race (p. 211).

We know this to be not true.

\section{NOTE}

1. See Table 2 for specific demographic data about the students. 


\section{REFERENCES}

Armas, G. C. (2001, March 13). U.S. minority populations increasing. The Laramie Daily Boomerang, p. 2.

Bohn, A. P., \& Sleeter, C. E. (2000). Multicultural education and the standards movement: A report from the field. Phi Delta Kappan, 82(2), 156-159.

Chamberlain, M., \& Thompson, P. R. (Eds.). (1998). Narrative and genre. New York: Routledge.

Coles, R. (1989). The call to stories: Teaching and the moral imagination. Boston: Houghton-Mifflin.

Curtin, D. (2001, February 3). Report hits teacher-ed programs. The Denver Post, pp. Bl, B3.

El Nasser, H, \& Overberg, P. (2001, March 28). Report: Cities, minorities lose in census undercount. LISA Today, p. 1A.

Festinger, L. (1957). A theory of cognitive dissonance. Stanford, CA: Stanford University Press.

Freire, P. (1987). Letter to North American teachers. In I. Shore (Ed.). Freire for the classroom (pp. 211-213). Portsmouth, NH: Heineman.

Glaser, B. G., \& Strauss, A. L. (1967). The discovery of grounded theory: Strategies for qualitative research. Chicago:Aldine.

Hammersley, M., \& Atkinson, P. (1995). Ethnography: Principles in practice (2nd ed.). New York: Routledge.

Hardy, B. (1977). Narrative as a primary act of mind. In M. M. Spencer, A. Warlow, \& G. Barton (Eds.), The cool web: The pattern of children's reading (pp. 12-23). London: Bodley Head.

Howard, G. R. (1999). We can't teach what we don't know: White teachers, multiracial schools. New York: Teacher's College Press.

Hubler, E. (2001, March 28). Activist targets Colorado bilingual program. The Denver Post, pp. Al, A18.

Inhelder, B., \& Piaget, J. (1958). The growth of logical thinking. New York: Basic.

Kanpol, B. (1992). The politics of similarity within difference: A pedagogy for the other. Urban Review, 24(2), 105-131.

Kivel, P. (1996). Uprooting racism: How white people can work for racial justice. Garbiola Island, BC, Canada: New Society.

Kohl, H. R. (1994). "I won't learn from you" and other thoughts on creative maladjustment. New York: New Press.

Ladson-Billings, G. (1992). Culturally relevant teaching: The key to making multicultural education work. In C. A. Grant (Ed.), Research and multicultural education: From the margins to the mainstream (pp. 106-121). London: Falmer.

Lee, E., Menkart, D., \& Okazawa-Rey, M. (1998). Introduction. In E. Lee, D. Menkart, \& M. Okazawa-Rey (Eds.), Beyond heroes and holidays: A practical guide to K-12 anti-racist, multicultural education and staff development (pp. vii-xii). Washington, DC: Network of Educators on the Americas.

Locke, D. C. (1988). Teaching culturally-different students: Growing pine trees or bonsai trees. Contemporary Education, 59(3), 130-133.

McCarthy, C. (1998). The uses of culture: Education and the limits of ethnic affiliation. New York: Routledge.

Rios, F. A., McDaniel, J. E., \& Stowell, L. P. (1998). Pursuing the possibilities of passion: The affective domain of multicultural education. In M. E. Dilworth (Ed.), Being responsive to cultural differences: How teachers learn (pp. 160-181). Thousand Oaks, CA: Corwin. 
Shor, I. (Ed.). (1987). Freire for the classroom: A sourcebook for liberatory teaching. Portsmouth, NH: Boynton/ Cook.

Francisco Rios is professor in the Department of Educational Studies at the University of Wyoming. His research interests include ethnic minority teachers and teaching, Latinos in education, multicultural teacher education, and teacher cognition in cultural contexts.

Allen Trent is an assistant professor in the Department of Educational Studies at the University of Wyoming. His research interests include action research, arts integrated education, and diversity in teacher education.

Lillian Vega Castañeda is professor and founding faculty member at the California State University—Channel Islands. Research interests include language and literacy in mainstream and multilingual contexts, community based education, and second language acquisition for English-only and English-learning children. 